\title{
Grafting polypropylene over hollow glass microspheres by reactive extrusion
}

\author{
Carlos André Baptista ${ }^{1,2}$ and Sebastião Vicente Canevarolo ${ }^{2 *}$ (i) \\ 13M do Brasil, Sumaré, SP, Brasil \\ 2Programa de Pós-graduação em Ciência e Engenharia de Materiais - PPG-CEM, Universidade Federal \\ de São Carlos - UFSCar, São Carlos, SP, Brasil \\ *caneva@ufscar.br
}

\begin{abstract}
Hollow glass microspheres HGM are light, round, hollow, hydrophilic microspheres used to produce polyolefin composites with reduced density. To maintain mechanical strength, it is necessary to improve the adhesion between the polymer matrix and the microspheres, which is done by a compatibilizer. For polypropylene composites a maleic anhydride grafted polypropylene copolymer PP-g-MAH is employed. The melt mixing is done in a reactive extrusion when the maleic group of the compatibilizer reacts with hydroxyl groups present at the microspheres' surface, grafting a long PP chain. The aim of this work is to quantify the esterification grafting conversion and its efficiency during the reactive extrusion to the formation of PP/HGM composites compatibilized with PP-g-MAH. Techniques like TGA, FTIR and SEM were used to quantify the grafted PP content formed and the efficiency of the esterification reaction, which is mainly dependent of the compatibilizer concentration and reactive extrusion temperature.
\end{abstract}

Keywords: hollow glass microspheres, maleic anhydride, grafted polypropylene, reactive extrusion.

How to cite: Baptista, C. A., \& Canevarolo, S. V. (2019). Grafting polypropylene over hollow glass microspheres by reactive extrusion. Polímeros: Ciência e Tecnologia, 29(3), e2019037. https://doi.org/10.1590/0104-1428.06118

\section{Introduction}

Reactive extrusion takes place when the synthesis or modification of a polymeric material happens at the same time of its processing and shaping into an intermediate or finished plastic product ${ }^{[1]}$. A common way to promote polymer compatibility in a blend or composite is through copolymers with segments capable of specific interactions and/or chemical reactions with the other components. The copolymers may be added separately or formed in situ by blending suitably functionalized polymers ${ }^{[2]}$.

Functionalized polyolefin, and more particularly functionalized polypropylene (PP), were used to compatibilize a large number of polar polymers such as polyesters and polyamides, thus improving the properties and stability of immiscible polymer blends ${ }^{[3-5]}$. Polypropylene compatibilization with polar polymers can be due to specific interactions, such as hydrogen bonding, or as the formation of graft copolymers by reactions between the functions grafted over the PP and others existing in polar polymers. These reactions can be made through reactive extrusion processing.

Radical functionalization of $\mathrm{PP}$ by reactive extrusion is one of the common ways to graft functional groups to the PP chains. Among possible reactive monomers, one of the most important for PP is maleic anhydride (MAH). It generally improves the adhesion of PP to metals, glass fibers, or other polymers ${ }^{[6-8]}$. The grafting of maleic anhydride to PP has been prepared successfully in the

melt state, by reactive extrusion ${ }^{[9-11]}$, and in the presence of liquid solvents ${ }^{[7,12]}$, which creates the problem of removing the organic solvent after reaction. It is generally accepted that chain scission occurs during the peroxide initiated functionalization, and the maleic anhydride is grafted to the PP backbone ${ }^{[10]}$.

The use of this grafted PP as a compatibilizer on fiber composites has been widely reported in the literature ${ }^{[8,13-15]}$, and also specially on glass fibers ${ }^{[16,17]}$. Works done on natural fibers, such as from Felix et al. ${ }^{[18]}$, show that esterification reactions can occur between the maleic anhydride grafted to the PP chains and the hydroxyl groups present on the surface of such fibers. These applications lead to the polypropylene grafted to maleic anhydride (PP-g-MAH) also to be used as a compatibilizing agent on hollow glass microspheres composites.

The use of hollow glass microspheres (HGM) in different polymeric composites has been continuously explored by both scientific and industrial means. Its influence in a wide array of properties, such as reducing density ${ }^{[19]}$, thermal conductivity ${ }^{[20-22]}$, dielectric properties ${ }^{[23,24]}$, and increasing sound dampening ${ }^{[25]}$ have created important benefits to industrial sectors such as automotive, electronics, mechanical and aerospace.

Despite its versatility and capacity to tinker several properties, using HGM in thermoplastic compounds usually diminishes the mechanical properties of the final product, 
such as tensile strength and impact resistance ${ }^{[26,27]}$, unless either a surface treatment and/or compatibilizers are used to enhance the interaction between HGMs and the polymeric matrix ${ }^{[19,21,28]}$. The works of Patankar et al. ${ }^{[21,29]}$, show that the use of $1 \%$ in weight of PE-g-MAH in a PE/HGM composite can positively influence toughness, yield strength and maximum strain of such composites. Kumar et al..$^{[15]}$, reported that the use of surface treated HGMs on PP and fiber composites improve mechanical properties while also reducing density. Patent literature of $3 \mathrm{M}^{[28]}$, shows an increase of approximately $40 \%$ on the tensile strength of $\mathrm{PP} / \mathrm{PP}-\mathrm{g}-\mathrm{MAH} / \mathrm{HGM}$ composites in comparison to composites without the compatibilizing agent. Even though these works show such effects, the content of PP grafted over the HGM and its efficiency has not been fully studied in PP/HGM composites compatibilized with maleic anhydride grafted polypropylene PP-g-MAH.

Given the need to create light and mechanically strong composites, and the economic advantage of the high yield provided by reactive extrusion, the goal of the present work is to assess both conversion and efficiency of the grafting reaction during reactive extrusion of a PP/PP-g-MAH/HGM composite, while analyzing the effect of the extrusion temperature in the process.

\section{Materials and Methods}

\subsection{Materials}

The major component of the composite is a commercial isotatic homopolypropylene (H301) with medium flow rate (MFI $10 \mathrm{~g} / 10 \mathrm{~min}$ ), and normal molecular weight distribution, produced by Braskem. Hollow glass microsphere $\left(3 \mathrm{M}^{\mathrm{TM}} \mathrm{iM} 16 \mathrm{k}\right)$ is an injection molding grade HGM, with high pressure resistance, produced by $3 \mathrm{M}$ Company and donated by $3 \mathrm{M}$ do Brasil LTDA. The PP-g-MAH (Polybond ${ }^{\circledast}$ PB 3200), produced and donated by Addivant ${ }^{\mathrm{TM}}$ has a nominal content of maleic anhydride of $1 \%$ weight, and MFI of $115 \mathrm{~g} / 10 \mathrm{~min}$. Materials were used as received without any further purification.

\subsection{Methods}

\subsubsection{Reactive extrusion}

The reactive extrusion was carried out in a co-rotating twin-screw extruder from HAAKE, Rheomex OS PTW24 model, with a $24 \mathrm{~mm}$ screw, $\mathrm{L} / \mathrm{D}=25$ and a side feeder at $\mathrm{L} / \mathrm{D}=12$. The screw was designed to have only conveying screw elements between the side feeder and die exit, to help diminish the breakage of $\mathrm{HGMs}^{[19]}$. The rotation speed was $50 \mathrm{rpm}$ and extrusion temperatures, kept constant along the whole barrel, were set at $200{ }^{\circ} \mathrm{C}, 220^{\circ} \mathrm{C}$ and $240{ }^{\circ} \mathrm{C}$. All components were oven dried for 12 hours at $80^{\circ} \mathrm{C}$ prior to melt mixing. Manually mixed formulations of PP and PP-g-MAH pellets were fed through the main feeder and HGMs were fed on the side feeder. The content of HGM was fixed at $10 \%(\mathrm{w} / \mathrm{w})$ in all formulations, the content of PP-g-MAH varied from $2 \%$ up to $14 \%(\mathrm{w} / \mathrm{w})$, adding up with the PP main component. The polymer melt while flowing inside an extruder spreads over many different path, with different length and shear histories, which results in a distribution of residence times. The shear level encountered by the melt and the residence time it stays inside the extruder directly affect the reaction conversion and so the breath of the residence time distribution RTD curve is important to be known, particularly when reactive extrusion is under study. For that the extrusion RTD curve was measured by adding a single pellet of colored PP tracer in the aperture of zone \#4, while the compositions were being prepared. To represent the RTD curve three main residence times were measured: initial time corresponding to the moment of the first sign of color exits the extruder which represents the fastest route the polymer melt flows, the peak time that of maximum color intensity when the biggest fraction of molten polymer exit the extruder and the final time when the slowest melt fraction exits the extruder, represented by the disappearance of the color in the extruded strands. This last fraction have taken the longest rote and probably faced the highest shear. A control composition containing only PP-g-MAH and HGMs $(10 \% \mathrm{w} / \mathrm{w})$ was prepared in a HAAKE torque rheometer at $200{ }^{\circ} \mathrm{C}$ for 10 minutes.

\subsubsection{Solution extraction of reacted hallow glass microspheres}

After reactive extrusion, $1.5 \mathrm{~g}$ of each compound was solubilized in $300 \mathrm{ml}$ hot xylene at $90{ }^{\circ} \mathrm{C}$ for two hours, enough to dissolve completely all soluble components. The suspension was then filtered with the help of a vacuum pump, leaving the PP grafted HGMs on the filter. The whole solution/filtering process was repeated twice for each sample.

\subsubsection{Quantification of the polypropylene grafted over the HGM microspheres using thermo-gravimetric analysis, TGA}

The PP grafted HGM samples were pyrolyzed in a TGA model Q50 from TA Instruments, available at the laboratories of $3 \mathrm{M}$ do Brasil LTDA, Sumaré, SP. The heating scans went up to $600{ }^{\circ} \mathrm{C}$ at $10^{\circ} / \mathrm{min}$ under a flow of compressed air. At least two samples were tested for each composition.

\subsubsection{Quantification of the polypropylene grafted over the HGM microspheres using infrared analysis, FTIR-ATR}

FTIR-ATR was performed in a Thermo Scientific, model Nicolet iS50, under Attenuated Total Reflectance, available at 3M do Brasil LTDA. Extruded strands were chopped and the fresh surface measured. Each composition was measured ten times, discarding the outliers, in order to attenuate the intrinsic limitations of the ATR technique. Reference PP/HGM compositions were prepared to produce the calibration curve by dissolving known amount of pristine $\mathrm{PP}$ in a round flask with hot xylene at $90^{\circ} \mathrm{C}$, until complete dissolution. Enough amount of HGM was added to prepare compositions with PP content varying from $1 \%$ to $12.5 \%$ $(\mathrm{w} / \mathrm{w})$ and well stirred. The mixture was poured on a glass plate and dried at $75^{\circ} \mathrm{C}$ for 12 hours. Portions of the dried mixture was squeezed over the ATR crystal window and the spectra taken. The known added weight's ratio between both components were related to the area under the absorbance bands present between $2970 \mathrm{~cm}^{-1}$ and $2840 \mathrm{~cm}^{-1}$ (referring to the symmetric and asymmetric stretch of the aliphatic $\mathrm{CH}_{2}$ and $\mathrm{CH}_{3}$, taken here as an indication the organic PP content) and the area of the bands present between $1300 \mathrm{~cm}^{-1}$ and $880 \mathrm{~cm}^{-1}$ (referring to the hollow glass microspheres inorganic phase content $)$ as Peak Area Ratio $=($ Peak Area from 2970 to 2840)/(Peak Area from 1300 to 880). Area 
instead of the absorbance at peak maxima was chosen because the PP content in the extrude grafted compound is low and the silica band is quite broad. A straight line was obtained and used to quantify the grafted PP content on the solvent extracted HGM after the reactive extrusion.

\subsubsection{Electron microscopy SEM and elemental analysis EDS}

Micrographs of the extruded compounds were taken by a scanning electron microscope FEI Inspect, model S50, available at 3M do Brasil LTDA. Extruded strands of PP/PP-g-MAH/HGM composites were cryogenically fractured, silver glued, gold sputtered and examined under various magnifications. The atomic concentration of $\mathrm{C}, \mathrm{O}$, $\mathrm{Na}, \mathrm{Si}$ and $\mathrm{Ca}$ on the surface of the HGM particles in some selected areas was quantified by energy-dispersive X-ray spectroscopy EDS analysis.

\section{Results and Discussions}

\subsection{Simulation of maximum PP grafting content over glass microspheres}

To simulate the maximum amount of polypropylene that could be attached to the surface of the HGM spheres a simple model was built. The area to be covered can be obtained from the mean diameter of the spheres $(20 \mu \mathrm{m})$ and the density of the spheres $\left(0.46 \mathrm{~g} / \mathrm{cm}^{3}\right)$. The maximum number of PP chains that could graft at the surface of one HGM can be estimated assuming that the minimum average cross section area of an extended single PP chain is that of the maximum packing of its crystalline unit cell. Knowing that its unit cell parameters are $\mathrm{a}=6.65 \AA$ and $\mathrm{b}=20.96 \AA$ and that there are four PP chains per unit cell we reach to the minimum cross section area of a PP chain is $34.85 \AA^{2}$, i.e. a diameter of $6.66 \AA$. From this we get that the maximum weight content of grafted PP chains that could fit over the surface of HGM is $\mathrm{w}_{\text {PPgMAH }}^{\max }(\%)=3.11 * 10^{-4} * \overline{\mathrm{M}_{\mathrm{n}}}$. By assuming that the number average molecular weight of the PP-g-MAH is in the range of $\overline{\mathrm{M}_{\mathrm{n}}}=70,000 \mathrm{~g} / \mathrm{mol}$, one can find that the maximum weight content of grafted PP chains is $\mathrm{w}_{\mathrm{PPgMAH}}^{\max } \cong 22 \% \mathrm{w} / \mathrm{w}$.

\subsection{Average residence times during extrusion}

Table 1 shows the average residence times during the extrusion of the composites measured from the entrance port (feeding hoper) of the HGM particles $(\mathrm{L} / \mathrm{D}=12)$ until the die exit, at three different extrusion temperatures. The increase of extrusion temperature reduces the melt viscosity and so facilitates the particle/polymer melt mixing, which, in turn, reduces the average residence time. This shorten the time the reactive processing has to graft the PP chains over the HGM surface. The neat final time/temperature effect in the grafting efficiency will be discussed later and is one of the objectives of this paper.

Table 1. Average residence times measured from the HGM's extrusion entrance port (zone \#4).

\begin{tabular}{lccc}
\hline \multicolumn{1}{c}{ Extrusion temperature } & $\mathbf{2 0 0}^{\circ} \mathbf{C}$ & $\mathbf{2 2 0}^{\circ} \mathbf{C}$ & $\mathbf{2 4 0}^{\circ} \mathbf{C}$ \\
\hline Initial residence time (s) & 65 & 60 & 55 \\
Peak residence time (s) & 90 & 85 & 75 \\
Final residence time (s) & 180 & 140 & 110 \\
\hline
\end{tabular}

\subsection{PP grafting content quantified by thermo-gravimetric TGA measurements}

The dried HGMs after solvent extraction were pyrolyzed in a TGA to quantify their organic content, which is assumed to be made solely by grafted PP chains. Pyrolyzed dried pristine HGM shows a maximum weight reduction of less than $0.4 \% \mathrm{w} / \mathrm{w}$. Figure 1 shows TGA curves for PP grafted HGM after solvent extraction, that have being made by reactive extrusion of PP/PP-g-MAH/HGM composites at 200 ${ }^{\circ} \mathrm{C}$, with varying PP-g-MAH content, ranging from $2 \%$ up to $14 \% \mathrm{w} / \mathrm{w}$. The drop in weight starts at approximately 300 ${ }^{\circ} \mathrm{C}$ spanning the pyrolysis up to almost $500{ }^{\circ} \mathrm{C}$. The burning process happens continuously and in only one degradation mechanism, above $500{ }^{\circ} \mathrm{C}$ the residue weight keeps constant indicating that all organic component has being pyrolyzed. The higher the PP-g-MAH content in the initial extruded formulation the higher the weight loss, i. e. the higher the grafted PP chains content.

Figure 2 shows curves of the amount of grafted PP chains over the extracted HGM as a function of the initial content of PP-g-MAH compatibilizer (in terms of $1 / \sqrt{\mathrm{W}_{\mathrm{PPgMAH}}}$ ) used during reactive extrusion, at three different temperatures. The content of PP chains grafted to the HGM's particles increases with the content of PP-g-MAH compatibilizer

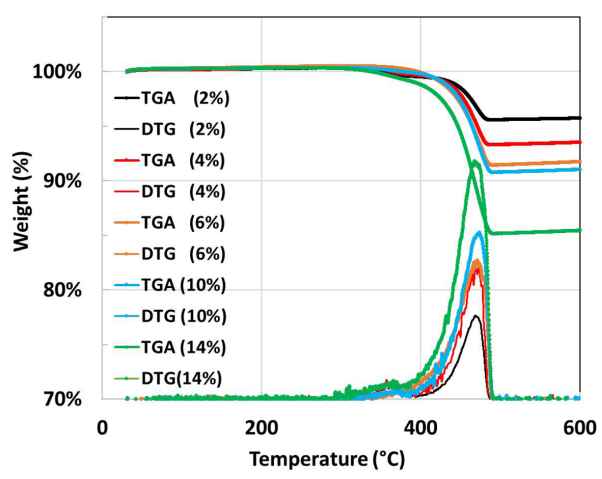

Figure 1. TGA/DTG curves of PP grafted onto hollow glass microsphere HGM compound, after solvent extraction. The organic pyrolyzed content correspond to the grafted $\mathrm{PP}$ content. The grafted compounds were extracted from PP/PP-g-MAH/HGM composites extruded at $200^{\circ} \mathrm{C}$, with varying PP-g-MAH content, as indicated.

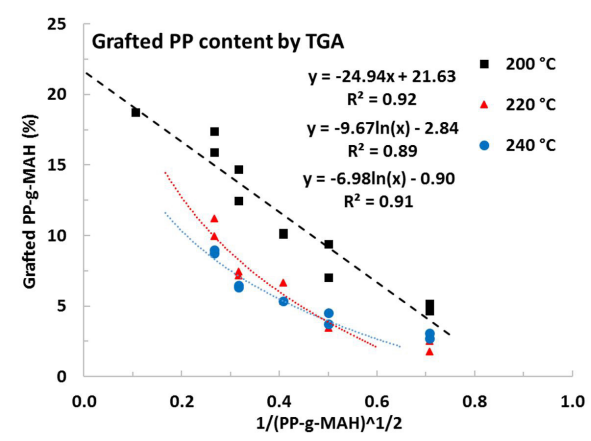

Figure 2. Grafted PP content over the extracted HGM measured by thermo-gravimetric analysis as a function of the initial content of PP-g-MAH compatibilizer used during reactive extrusion. The extrapolated value of $21.6 \%$ is the maximum PP grafting content. 
added to the reactive extruded compound, indicating that more ester bonds are created as PP-g-MAH compatibilizer chains becomes more available. For reactive extrusion at $200^{\circ} \mathrm{C}$ the data follows a straight line which extrapolates to the maximum weight of PP chains that can be grafted over the HGM particles, which is $\mathrm{w}_{\mathrm{PPgMAH}}^{\max }=21.6 \%$, a value very close to the simulated data using $\overline{\mathrm{M}}_{\mathrm{n}}^{\mathrm{PPMAH}}=70,000 \mathrm{~g} / \mathrm{mol}$. To reach this limiting condition, it is necessary to use samples of PP-g-MAH in which all PP chains are grafted with maleic anhydride, which does not happens in commercial samples, given that not all chains get grafted during its reaction ${ }^{[7]}$.

Upon rising the reactive extrusion temperature of the composite to $220^{\circ} \mathrm{C}$ and $240{ }^{\circ} \mathrm{C}$ the efficiency of the PP grafting content on the HGM particles reduces. It is known that the monoesterification reaction between styrene-maleic anhydride and aliphatic alcohols decreases significantly with increasing temperature ${ }^{[30]}$. Another effect is that, at higher reactive extrusion temperatures the time available to the reaction, $i$. e. the average residence time during extrusion is greatly reduced, as shown in Table 1 . Together both effects reduce the grafting efficiency of the reaction leading to a lower total conversion.

To prepare a formulation as close as possible to the maximum compatibilizer content in the composite, HGM particles with pure PP-g-MAH were mixed in a HAAKE rheometer. In doing so it was possible to get the datum at $1 / \sqrt{\mathrm{w}_{\mathrm{PPgMAH}}}=1.05$ which reaches to a PP grafted content of $\mathrm{w}_{\mathrm{PPgMAH}}=18.72 \%$. The HAAKE mixing time was $600 \mathrm{~s}$, well above the average residence time of the extrusion, allowing plenty of time for the reaction to occur.

The presence of organic material in the HGMs after the hot solvent extraction indicates that it is covalently bounded (some hydrogen bonds may be formed as well) to the surface of the microspheres, grafted during the reactive extrusion. Figure 3 shows such a reaction, proposed by Felix et al. ${ }^{[18]}$ for grafting PP-g-MAH over cellulose fibers. The maleic anhydride functional groups in the PP-g-MAH chains react with the hydroxyl groups present in the HGM's surface forming ester bonds, grafting the copolymer. The layer of PP chains over the HGM particles more efficiently anchor them in the polymer matrix producing composites with improved mechanical properties, as mentioned in various works ${ }^{[28,29]}$, by improving the load transfer on the composite's interface ${ }^{[31]}$.

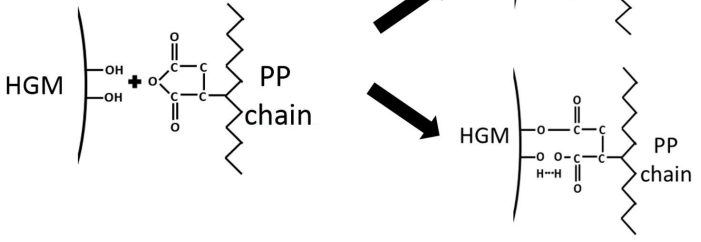

Figure 3. Proposed grafting mechanisms of the maleic anhydride functional group present in the PP-g-MAH compatibilizer and hydroxyl groups present on the surface of the HGMs particles (adapted $^{[18]}$ ).

\subsection{Efficiency of PP grafting over HGM measured by TGA}

The PP grafting over the hollow glass microspheres is needed for a better anchoring which leads to an efficient load transfer during mechanical stress. The mixing method used here is by reactive extrusion in which the polymer matrix and the compatibilizer are added to the extruder in the first feeding zone and the HGM downstream by a side feeder located at $\mathrm{L} / \mathrm{D}=12$ to reduce, as much as possible, the breakage of the HGM microspheres. In addition, any high shearing screw elements, like kneading elements, should be added in the screw profile only prior to the side feeder entrance and having none downstream. In doing so the PP-g-MAH compatibilizer is mixed and diluted in the PP matrix prior to be able to get in contact with the HGM. When it does the amount of compatibilizer is proportionally reduced according to the initial feeding composition. The grafting efficiency, i.e. how much the fed PP-g-MAH content actually reacts, producing the grafted layer over the glass microspheres, should be calculated. We choose to quantify the efficiency by calculating the weight percentage of grafted PP over the HGM microspheres measured by the TGA analysis, in relation to the original total mass of PP/PP-g-MAH/HGM fed to the extruder. The experiment covered five different compatibilizer concentrations and three reactive extrusion temperatures.

Figure 4 shows bar curves of PP-g-MAH compatibilizer content (in gray) present in the initial composite formulation and the correspondent grafted $\mathrm{PP}$ content (in blue), at reactive extrusion temperatures of $200^{\circ} \mathrm{C}, 220^{\circ} \mathrm{C}$ and $240^{\circ} \mathrm{C}$. All contents are in $\% \mathrm{w} / \mathrm{w}$, and are relative to the initial composition fed into the extruder. Finally, a linear fitting curve is added to the PP grafted content, obtained from the TGA analysis.

Analyzing Figure 4 one immediately observes that the amount of PP-g-MAH grafted over the HGM is very low compared to the amount initially added. The diluting effect of the PP-g-MAH in the PP matrix along the extruder, until reaching the side feeder, reduces the reagent content for the esterification reaction to occur. As already observed the grafting conversion reduces at higher extrusion temperatures. Knowing that the HGM content in the original formulation is $10 \%$ then the simulated maximum grafting content would reach to $\mathrm{w}_{\mathrm{PPgMAH}}^{\max }=2.16 \%$. The highest grafting content obtained was $1.66 \%$, reacting at the minimum extrusion temperature $200{ }^{\circ} \mathrm{C}$ and at the maximum PP-g-MAH compatibilizer content used here of $14 \%$. This level of compatibilizer content is already too high, and lowering the extrusion temperature even further would increase the melt viscosity and so the extrusion torque, hindering the process.

In order to remedy the low efficiency various strategies should be applied, such as: design the screw profile to improve microspheres dispersion as well as avoiding their breakage, feed the compatibilizer downstream as close as possible to the feeding microspheres' port, premix the microspheres with the compatibilizer as a master concentrate, set the extrusion temperature profile in the reaction zone as low as possible, i.e. downstream after the microspheres feeding port, and so on. 

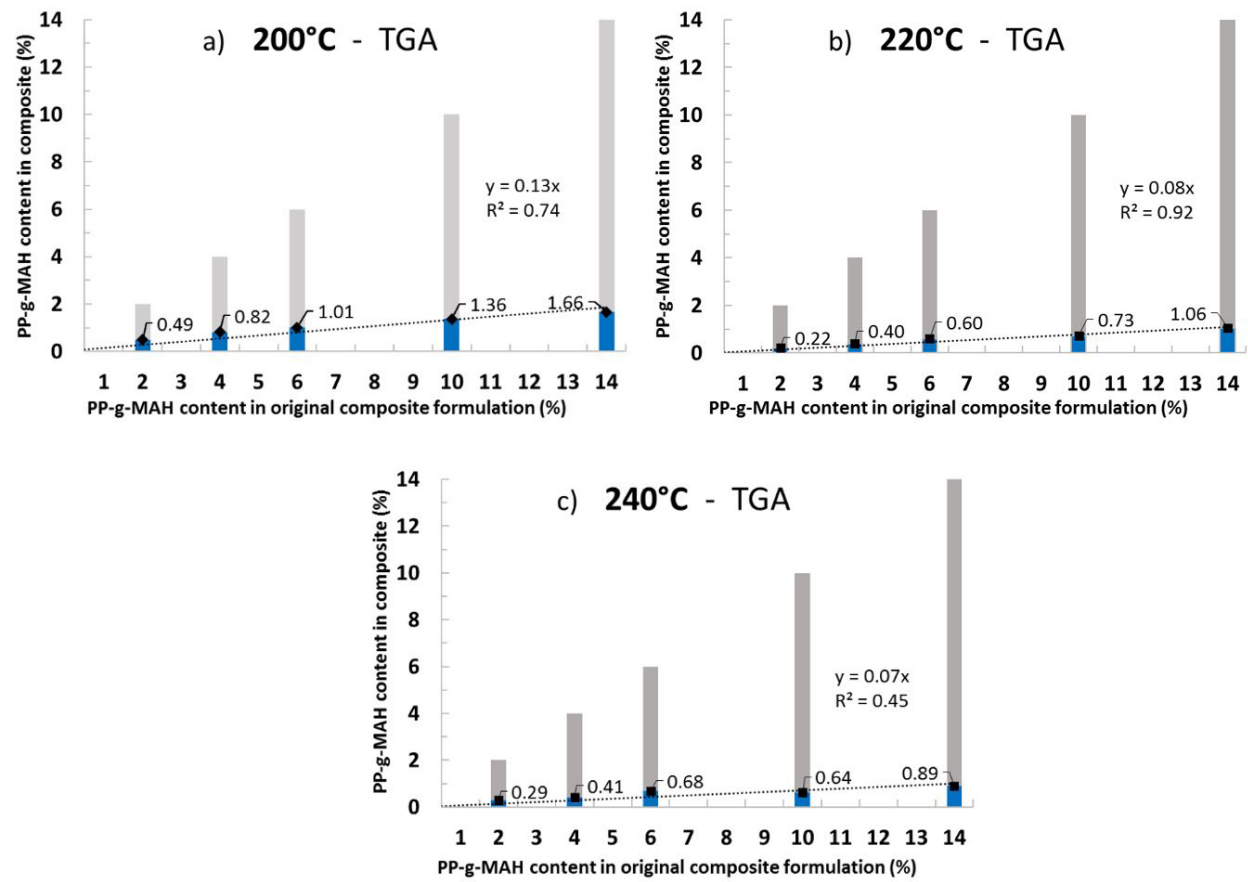

Figure 4. Efficiency curves from TGA analysis in terms of added PP-g-MAH compatibilizer and grafted PP contents, at various reactive extrusion temperatures, as indicated. Gray bars represent PP-g-MAH in the initial composite formulation, blue bars show the PP grafted content. All contents are in $\% \mathrm{w} / \mathrm{w}$ and relates to the initial composition fed in the extruder. Linear fitting curves.

\subsection{FTIR-ATR spectra of PP/HGM compound and its calibration curve}

Figure 5 shows the infrared spectra of a PP grafted HGM after solvent extraction from an extruded original formulation with $14 \%$ of PP-g-MAH and $10 \%$ HGM at $220^{\circ} \mathrm{C}$. Two main sets of bands are present: i) bands between $2970 \mathrm{~cm}^{-1}$ and $2840 \mathrm{~cm}^{-1}$, referring to the symmetric and asymmetric stretch of aliphatic $\mathrm{CH}_{2}$ and $\mathrm{CH}_{3}{ }^{[32]}$ bands, and ii) a broad band, between $1300 \mathrm{~cm}^{-1}$ and $880 \mathrm{~cm}^{-1}$, referring to the $1100 \mathrm{~cm}^{-1} \mathrm{SiO}_{2}$ silica bonds of the HGM. A 10x enlarged portion of the spectra, in the $4000-2300 \mathrm{~cm}^{-1}$ range, is shown to highlight the PP band, present in low quantities in the PP grafted HGM solvent extracted compound. The quantification is done by measuring the area under each band, employing a horizontal straight base-line, as shown in Figure 5.

The sensitivity of the FTIR-ATR method to quantitatively measure the expected low levels of the grafted PP content over the solvent extracted HGM was checked by obtaining a calibration curve from mixtures of PP homopolymer and HGM pristine microspheres, in the expected grafted PP content range of the composites. The areas under the PP and silica bands was measured and their ratio calculated resulting the calibration curve presented in Figure 6. The data points fit quite well in a straight line, with $\mathrm{R}^{2}=0.997$, good enough to allow the use of the FTIR-ATR method to quantitatively characterize the content of the grafted PP over the solvent extracted HGM microspheres.

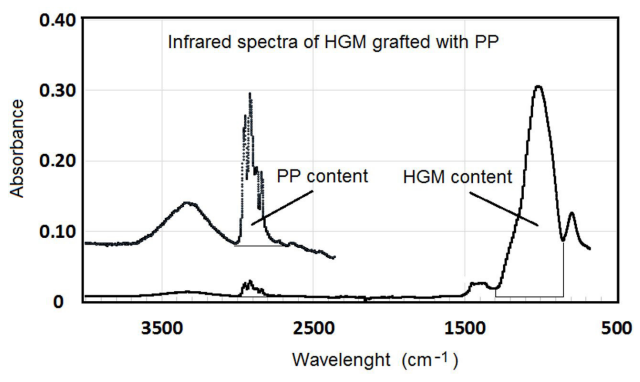

Figure 5. FTIR spectra of a PP grafted HGM after solvent extraction from an extruded original formulation with $14 \%$ of PP-g-MAH and $10 \% \mathrm{HGM} \mathrm{w} / \mathrm{w}$ at $220^{\circ} \mathrm{C}$. The spectra above $2300 \mathrm{~cm}^{-1}$ is shown enlarged 10x in the upper shifted curve. The quantification is done taking the area under each band, as shown.

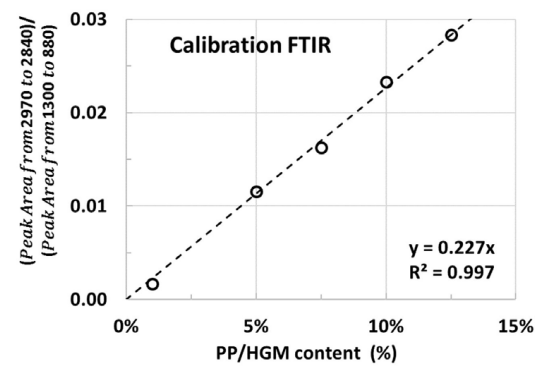

Figure 6. FTIR calibration curve of PP/HGM reference mixtures as curves of Peak Area Ratio $=\frac{(\text { Peak Area from } 2970 \text { to } 2840)}{(\text { Peak Area from1300 to } 880)}$ as a function of the PP/HGM weight content (\%). 


\subsection{PP grafting content quantified by FTIR-ATR measurements}

The amount of grafted PP over the HGM microspheres was also quantified by FTIR/ATR. Figure 7 shows the same set of curves for the three extrusion temperatures as used during the TGA quantification. The behavior, as expected, is almost the same. Both techniques can quantify almost equally the grafting yield. Again data for $200{ }^{\circ} \mathrm{C}$ follow a straight line which extrapolate to $\mathrm{w}_{\mathrm{PPgMAH}}^{\max }=19.4 \%$, within the experimental error of the value obtained by TGA. The behavior at higher extrusion temperature $\left(220^{\circ} \mathrm{C}\right.$ and $\left.240{ }^{\circ} \mathrm{C}\right)$ also shows a reduction in the PP grafting conversion over the HGM particles, agreeing with the expected reduction in the

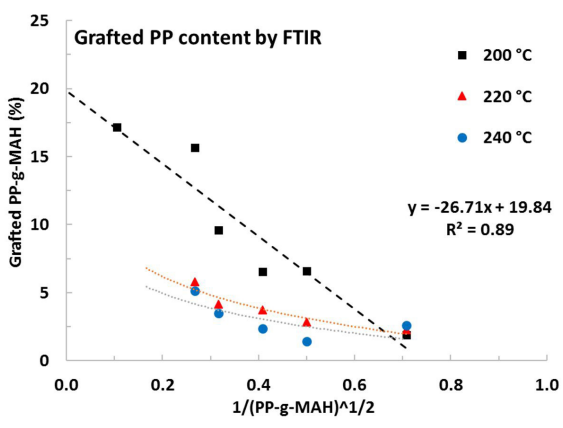

Figure 7. Grafted PP content over the extracted HGM measured by FTIR-ATR method as a function of the initial content of PP-g-MAH compatibilizer used during reactive extrusion. The maximum PP grafting content is the extrapolated value of $19.8 \%$. conversion of the esterification reaction between maleic anhydride and alcohols with increasing temperature ${ }^{[30]}$. The already mentioned reduction in the average residence time during extrusion at higher temperatures also contributes to the reduction in grafting efficiency.

The FTIR-ATR measurements gives higher data dispersion, partially due to the great difference between the band area of the aliphatic $\mathrm{CH}_{2}$ and $\mathrm{CH}_{3}$ of $\mathrm{PP}$ and the band area of silica, when calculating their ratio. The FTIR-ATR spectra (Figure 5) also does not show peaks at $1780 \mathrm{~cm}^{-1}$, which would correspond to the carbonyl group in cyclic anhydrides, nor at $1746 \mathrm{~cm}^{-1}$, which would correspond to ester bonds on the HGM's surface ${ }^{[18]}$. This indicates that the amount of ester bonds is below the detection, just as indicated by Patankar et al. ${ }^{[29]}$, and expected by the slow reaction kinetics of maleic anhydride to hydroxyl groups ${ }^{[33]}$. Even though, it is still possible to detect the polypropylene chain grafted to these bonds, hence TGA and FTIR technique were used to quantify it.

\subsection{Efficiency of PP grafting over HGM measured by FTIR}

The efficiency of the total reaction was calculated the same way as done for the TGA samples. Figure 8 shows how much of the initial compounded PP-g-MAH reacted. Again the low grafting efficiency is also revealed by the FTIR-ATR analysis, the reaction consumes only a small portion of the initially fed content of PP-g-MAH compatibilizer. Even if this technique presents a slightly more dispersed data, the conclusions drawn from both analysis are the same, no more than $10 \%$ of the added PP-g-MAH in the original extruded formulation is grafted onto the HGM microspheres.
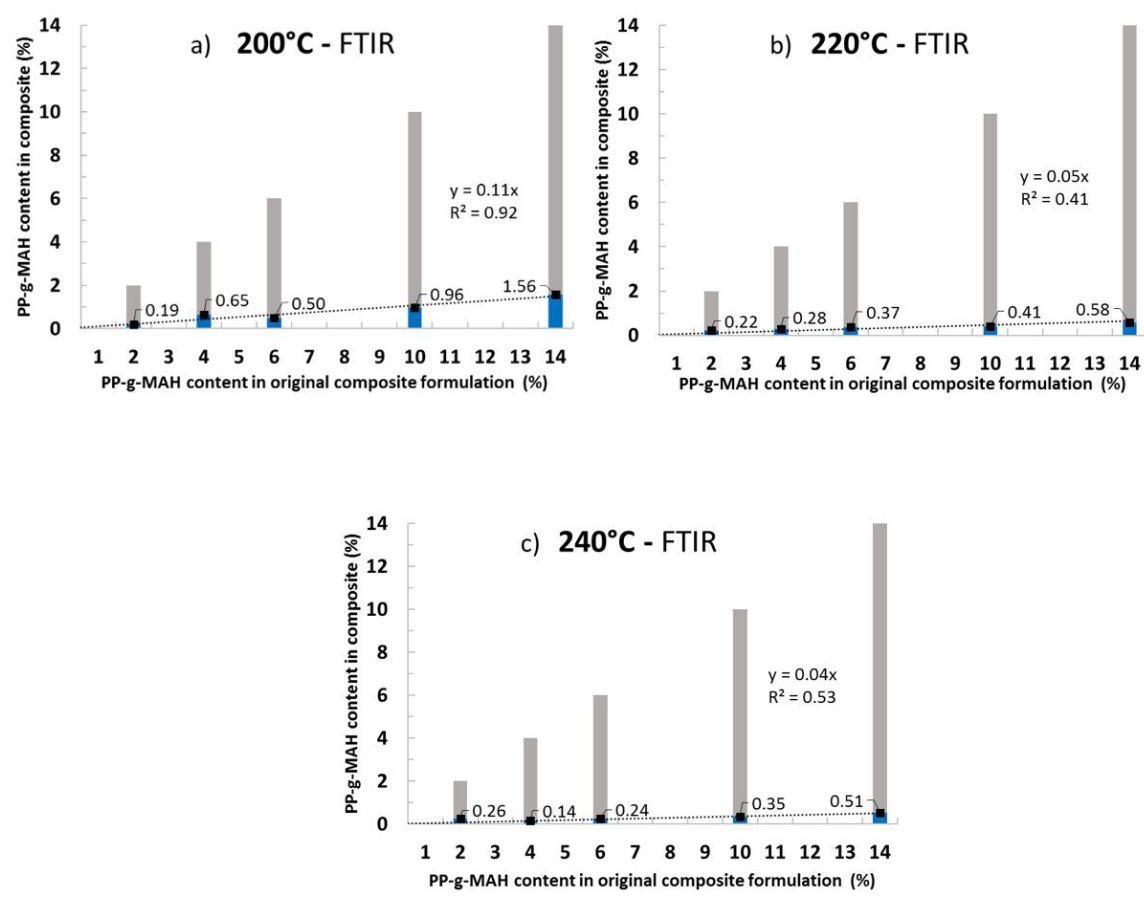

Figure 8. Efficiency curves from FTIR analysis in terms of added PP-g-MAH compatibilizer and grafted PP contents, at various reactive extrusion temperatures, as indicated. Gray bars represent PP-g-MAH in the initial composite formulation, blue bars show the PP grafted content. All contents are in $\% \mathrm{w} / \mathrm{w}$ and relates to the initial composition fed in the extruder. Linear fitting curves. 


\subsection{SEM micrographs and EDS analysis of the composite fractured surface}

As seen so far, the content of the grafted PP over the surface of the HGM particles measured by TGA and FTIR techniques is dependent of the concentration of the PP-g-MAH compatibilizer added in the composite formulation. The anchoring effect of this polymeric layer is expected to improve the mechanical properties of the composite ${ }^{[28]}$. Figure 9 shows SEM micrographs of cryogenically fractured extruded strands of the uncompatibilized PP/HGM (Figure 9a) and compatibilized with $14 \%$ of PP-g-MAH (Figure 9b) composites. The difference of the interface in both cases is clearly evidenced, on the uncompatibilized composite the interaction between the PP polymer matrix and the HGM particle is almost inexistent, the round glass particles are detached from the matrix, very little load transfer during mechanical deformation can be expected. On the contrary, in the PP-g-MAH compatibilized composite there is a smooth change from the matrix to the glass particle, no clear interface is seen. The particle is well immersed in the matrix, with layers of the organic matrix covering it, an interaction that gives a good load transfer during mechanical deformation.

Figure 9 also shows selected points (crosses) on the surface of the hollow glass microspheres in which weight and atomic concentrations of $\mathrm{C}, \mathrm{O}, \mathrm{Na}, \mathrm{Si}$ and $\mathrm{Ca}$ were measured by EDS analysis. The data are presented in Table 2. The particle surface of uncompatibilized PP/HGM composite seen in Figure 9a show low levels of carbon and high levels of silicon and calcium atoms (marked \#1). On the other hand, the compatibilized PP/PP-g-MAH/HGM composite (Figure $9 \mathrm{~b}$ ) shows a much higher concentration of carbon and lower for silicon and calcium atoms (\#2), indicating the presence of an organic layer covering the entire glass particle surface. Moreover, selecting another area in this same compatibilized composite (\#3) in which a visible extra layer was left over the glass particle, while the crack was propagating, the carbon concentration increases even further, in detriment to the silicon and calcium atoms content (see Table 2). This is a quantitative indication that there are PP chains adhered to the HGM surface, result of the grafting reaction occurred during the compatibilized reactive extrusion.

\section{Conclusions}

This paper quantifies the conversion and efficiency of the esterification reaction between the maleic anhydride from a maleate polypropylene (PP-g-MAH) to graft onto hollow glass microspheres HGM. They are dependent on both, the initial content of available PP-g-MAH in the composite formulation and the reactive extrusion temperature.

The reaction conversion increases with the PP-g-MAH content in the formulation, topping near the theoretical limit of approximately $20 \% \mathrm{w} / \mathrm{w}$ of grafted PP over the HGM

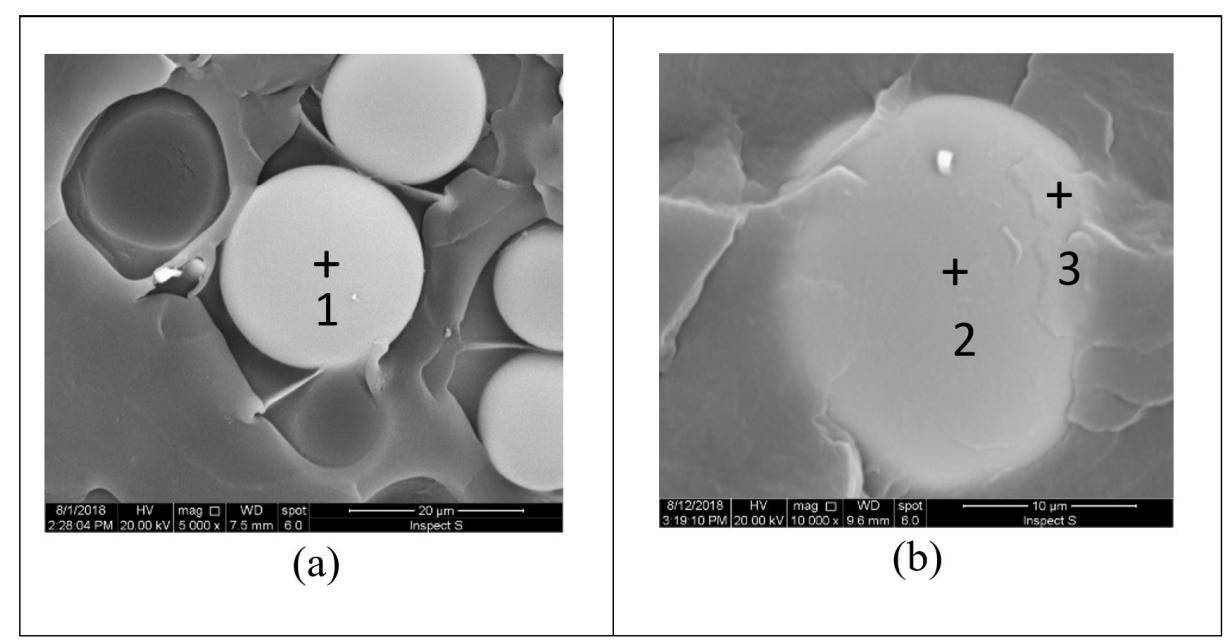

Figure 9. SEM images of cryogenically fractured composites: (a) uncompatibilized PP/HGM composite showing clean detached HGM particle from the PP matrix, (b) compatibilized PP/PP-g-MAH/HGM composite with well-anchored interface matrix/HGM particle. Crosses show approximate locations were the concentration of carbon, silicon and other atoms was measured, with data shown in Table 2. Note that location \#3 is over an extra layer of PP.

Table 2. Weight and atomic concentrations of $\mathrm{C}, \mathrm{O}, \mathrm{Na}, \mathrm{Si}$ and $\mathrm{Ca}$ over the surface of the HGM particles in selected areas, as indicated in Figure 9.

\begin{tabular}{|c|c|c|c|c|c|c|}
\hline \multirow{2}{*}{ Atom } & \multicolumn{2}{|c|}{ Uncomp. 1} & \multicolumn{2}{|c|}{ Graf 2} & \multicolumn{2}{|c|}{ Graf 3} \\
\hline & $\mathbf{w}(\%)$ & Atom.(\%) & $w(\%)$ & Atom.(\%) & $w(\%)$ & Atom.(\%) \\
\hline $\mathrm{C}$ & 14.1 & 23.2 & 23.0 & 34.9 & 36.9 & 49.8 \\
\hline $\mathrm{O}$ & 34.8 & 42.9 & 33.8 & 38.5 & 32.9 & 33.4 \\
\hline $\mathrm{Na}$ & 2.4 & 2.1 & 2.2 & 1.8 & 2.1 & 1.5 \\
\hline $\mathrm{Si}$ & 37.2 & 26.1 & 31.9 & 20.7 & 22.3 & 12.9 \\
\hline $\mathrm{Ca}$ & 11.5 & 5.7 & 9.0 & 4.1 & 5.8 & 2.3 \\
\hline
\end{tabular}


microspheres. As expected, an increase in the extrusion temperature reduces the esterification reaction conversion, reducing the grafted PP content.

The traditional way of adding the PP-g-MAH compatibilizer with the polymer matrix promotes its dilution in a large amount of material and so most of it remains unreacted in the PP matrix, reducing its efficiency. The results also highlights the importance in choosing the right screw profile to get a good balance between be mild enough to avoid the HGM's breakage, but enough shearing to grant high efficiency to the esterification reaction and so the grafting conversion.

\section{Acknowledgements}

This study was financed in part by the Coordenação de Aperfeiçoamento de Pessoal de Nível Superior - Brasil (CAPES) - Finance Code 001, to Conselho Nacional de Desenvolvimento Científico e Tecnológico, CNPq (for granting the research scholarship PQ 311790/2013-5 to S.V. Canevarolo) and to the Programa de Pós-Graduação em Ciência e Engenharia de Materiais (PPG-CEM) of UFSCar for providing its research facilities. C. A. Baptista acknowledges 3M do Brasil LTDA, Sumaré, SP, for allowing him the develop this research, donating the materials and lending their facilities.

\section{References}

1. Tzoganakis, C. (1989). Reactive extrusion of polymers: a review. Advances in Polymer Technology, 9(4), 321-330. http:// dx.doi.org/10.1002/adv.1989.060090406.

2. Xanthos, M., \& Dagli, S. S. (1991). Compatibilization of polymer blends by reactive processing. Polymer Engineering and Science, 31(13), 929-935. http://dx.doi.org/10.1002/ pen.760311302.

3. Tjong, S. C., \& Meng, Y. (1997). The effect of compatibilization of maleated polypropylene on a blend of polyamide- 6 and liquid crystalline copolyester. Polymer International, 42(2), 209-217. http://dx.doi.org/10.1002/(SICI)1097-0126(199702)42:2<209::AIDPI700>3.0.CO;2-P.

4. Zhihui, Y., Yajie, Z., Xiaomin, Z., \& Jinghua, Y. (1998). Effects of the compatibilizer PP-g-GMA on morphology and mechanical properties of PP/PC blends. Polymer, 39(3), 547551. http://dx.doi.org/10.1016/S0032-3861(97)00299-1.

5. Sun, Y. J., Hu, G. H., Lambla, M., \& Kotlar, H. K. (1996). In situ compatibilization of polypropylene and poly(butylene terephthalate) polymer blends by one-step reactive extrusion. Polymer, 37(18), 4119-4127. http://dx.doi.org/10.1016/00323861(96)00229-7.

6. Shashidhara, G. M., Biswas, D., Shubhalaksmi Pai, B., Kadiyala, A. K., Wasim Feroze, G. S., \& Ganesh, M. (2009). Effect of PP-g-MAH compatibilizer content in polypropylene/ nylon-6 blends. Polymer Bulletin, 63(1), 147-157. http://dx.doi. org/10.1007/s00289-009-0074-7.

7. Sathe, S. N., Rao, G. S. S., \& Devi, S. (1994). Grafting of maleic anhydride onto polypropylene: synthesis and characterization. Journal of Applied Polymer Science, 53(2), 239-245. http:// dx.doi.org/10.1002/app.1994.070530212.

8. Bledzki, A. K., Reihmane, S., \& Gassan, J. (1996). Properties and modification methods for vegetable fibers for natural fiber composites. Journal of Applied Polymer Science, 59(8), 1329-1336. http://dx.doi.org/10.1002/(SICI)10974628(19960222)59:8<1329::AID-APP17>3.0.CO;2-0.
9. Gaylord, N. G., \& Mishra, M. K. (1983). Nondegradative reaction of maleic anhydride and molten polypropylene in the presence of peroxides. Journal of Polymer Science. Polymer Letters Edition, 21(1), 23-30. http://dx.doi.org/10.1002/ pol.1983.130210104.

10. Shi, D., Yang, J., Yao, Z., Wang, Y., Huang, H., Jing, W., Yin, J., \& Costa, G. (2001). Functionalization of isotactic polypropylene with maleic anhydride by reactive extrusion: mechanism of melt grafting. Polymer, 42(13), 5549-5557. http://dx.doi.org/10.1016/S0032-3861(01)00069-6.

11. Moad, G. (1999). Synthesis of polyolefin graft copolymers by reactive extrusion. Progress in Polymer Science (Oxford), 24(1), 81-142. http://dx.doi.org/10.1016/S0079-6700(98)00017-3.

12. Minoura, Y., Ueda, M., Mizunuma, S., \& Oba, M. (1969). The reaction of polypropylene with maleic anhydride. Journal of Applied Polymer Science, 13(8), 1625-1640. http://dx.doi. org/10.1002/app.1969.070130805.

13. Saheb, D. N., \& Jog, J. P. (1999). Natural fiber polymer composites: A review. Advances in Polymer Technology, 18(4), 351-363. http://dx.doi.org/10.1002/(SICI)10982329(199924)18:4<351::AID-ADV6>3.0.CO;2-X.

14. Li, X., Tabil, L. G., \& Panigrahi, S. (2007). Chemical treatments of natural fiber for use in natural fiber-reinforced composites: a review. Journal of Polymers and the Environment, 15(1), 25-33. http://dx.doi.org/10.1007/s10924-006-0042-3.

15. Kumar, N., Mireja, S., Khandelwal, V., Arun, B., \& Manik, G. (2016). Light-weight high-strength hollow glass microspheres and bamboo fiber based hybrid polypropylene composite: a strength analysis and morphological study. Composites. Part B, Engineering, 109, 277-285. http://dx.doi.org/10.1016/j. compositesb.2016.10.052.

16. Mäder, E., Jacobasch, H. J., Grundke, K., \& Gietzelt, T. (1996). Influence of an optimized interphase on the properties of polypropylene/glass fibre composites. Composites. Part A, Applied Science and Manufacturing, 27(9), 907-912. http:// dx.doi.org/10.1016/1359-835X(96)00044-9.

17. Thomason, J. L., \& Schoolenberg, G. E. (1994). An investigation of glass fibre/polypropylene interface strength and its effect on composite properties. Composites, 25(3), 197-203. http:// dx.doi.org/10.1016/0010-4361(94)90017-5.

18. Felix, J. M., \& Gatenholm, P. (1991). The nature of adhesion in composites of modified cellulose fibers and polypropylene. Journal of Applied Polymer Science, 42(3), 609-620. http:// dx.doi.org/10.1002/app.1991.070420307.

19. Yalcin, B., \& Amos, S. E. (2015). Hollow glass microspheres in thermoplastics. In S. E. Amos \& B. Yalcin (Eds.), Hollow glass microspheres for plastics, elastomers, and adhesives compounds (Plastics Design Library, chap. 3, pp. 35-105). Elsevier. http:// dx.doi.org/10.1016/B978-1-4557-7443-2.00003-7.

20. Liang, J. Z. (2014). Estimation of thermal conductivity for polypropylene/hollow glass bead composites. Composites. Part B, Engineering, 56, 431-434. http://dx.doi.org/10.1016/j. compositesb.2013.08.072.

21. Patankar, S. N., Das, A., \& Kranov, Y. A. (2009). Interface engineering via compatibilization in HDPE composite reinforced with sodium borosilicate hollow glass microspheres. Composites. Part A, Applied Science and Manufacturing, 40(6-7), 897-903. http://dx.doi.org/10.1016/j.compositesa.2009.04.016.

22. Zhou, Y., Rangari, V., Mahfuz, H., Jeelani, S., \& Mallick, P. K. (2005). Experimental study on thermal and mechanical behavior of polypropylene, talc/polypropylene and polypropylene/clay nanocomposites. Materials Science and Engineering A, 402(12), 109-117. http://dx.doi.org/10.1016/j.msea.2005.04.014.

23. Zhu, B. L., Zheng, H., Wang, J., Ma, J., Wu, J., \& Wu, R. (2014). Tailoring of thermal and dieletric properties of LDPEmatrix composites by the volume fraction, density, and surface 
modification of hollow glass microsphere filler. Composites. Part B, Engineering, 58, 91-102. http://dx.doi.org/10.1016/j. compositesb.2013.10.029.

24. Zhu, B. L., Wang, J., Zheng, H., Ma, J., Wu, J., \& Wu, R. (2015). Investigation of thermal conductivity and dielectric properties of LDPE-matrix composites filled with hybrid filler of hollow glass microspheres and nitride particles. Composites. Part B, Engineering, 69, 496-506. http://dx.doi.org/10.1016/j. compositesb.2014.10.035.

25. Liang, J.-Z., \& Jiang, X.-H. (2012). Soundproofing effect of polypropylene/inorganic particle composites. Composites. Part B, Engineering, 43(4), 1995-1998. http://dx.doi.org/10.1016/j. compositesb.2012.02.020.

26. Liang, J. (2002). Tensile and impact properties of hollow glass bead- filled PVC composites. Macromolecular Materials and Engineering, 287(9), 588-591. http://dx.doi.org/10.1002/14392054(20020901)287:9<588::AID-MAME588>3.0.CO;2-6.

27. Liang, J.-Z. (2005). Mechanical properties of hollow glass bead-filled ABS composites. Journal of Thermoplastic Composite Materials, 18(5), 407-416. http://dx.doi. org/10.1177/0892705705051899.

28. Yalcin, B., Gunes, I. S., Carvalho, G. B., \& Williams, M. J. (2016). US20160326352A1. United States: United States Patent and Trademark Office.
29. Patankar, S. N., \& Kranov, Y.A. (2010). Hollow glass microsphere HDPE composites for low energy sustainability. Materials Science and Engineering A, 527(6), 1361-1366. http://dx.doi. org/10.1016/j.msea.2009.10.019.

30. Hu, G. H., \& Lindt, J. T. (1993). Monoesterification of styrene-maleic anhydride copolymers with alcohols in ethyl benzene: catalysis and kinetics. Journal of Polymer Science. Part A, Polymer Chemistry, 31(3), 691-700. http://dx.doi. org/10.1002/pola.1993.080310313.

31. Feldman, D., \& Lacasse, M. A. (1994). Polymer-filler interaction in polyurethane kraft lignin polyblends. Journal of Applied Polymer Science, 51(4), 701-709. http://dx.doi.org/10.1002/ app.1994.070510416.

32. Kuptsov, A. H., \& Zhizhin, G. N. (1998). Handbook of fourier transform raman and infrared spectra of polymers. Amsterdam: Elsevier Science.

33. Orr, C. A., Cernohous, J. J., Guegan, P., Hirao, A., Jeon, H. K., \& Macosko, C. W. (2001). Homogeneous reactive coupling of terminally functional polymers. Polymer, 42(19), 8171-8178. http://dx.doi.org/10.1016/S0032-3861(01)00329-9.

Received: Jan. 22, 2019

Revised: June 21, 2019 Accepted: Aug. 01, 2019 